\title{
PSEUDO-MEIGS' SYNDROME ASSOCIATED TO RENAL PELVIS TUMOR
}

\author{
CHIARA S. TESSMER, FRANKLIN C. BARCELLOS, LUIZ C. FALCHI \\ Section of Urology, Hospital Santa Casa de Pelotas, Catholic University of Pelotas, Federal University of \\ Pelotas, RS, Brazil
}

\begin{abstract}
Introduction: Pseudo-Meigs' syndrome is associated with tumors different from the benign ovary tumor, but it has never been described in association to transitional cell carcinoma.

Case Report: A female 73 year-old patient presenting pleural effusion nonmetastatic associated with renal pelvis transitional cell carcinomathat resolved and did not recur after radical nephroureterectomy.

Comments: Renal pelvis transitional cell carcinoma can result in the Pseudo-Meigs' syndrome. Although being a rare clinical entity, the identification of such syndrome can result in an accurate diagnosis, leading to an efficient surgical treatment, without comorbidity for the patient.
\end{abstract}

Key words: kidney; carcinoma, transitional cell; Meigs' syndrome; pleural effusion

Int Braz J Urol. 2005; 31: 256-8

\section{INTRODUCTION}

Meigs \& Cass (1) described the Meigs' syndrome from case reports of patients with right pleural effusion and ascites associated with benign ovary tumor, which were resolved after the removal of the ovarian lesion. The name pseudo-Meigs' syndrome is used to describe the same clinical situation, but only when it is caused by tumors different from benign ovary tumor (1).

\section{CASE REPORT}

Female patient, 73 year-old, admitted with hematuria, weight loss and dyspnea. Examination of the thorax showed reduction of the vesicular murmur in the right pulmonary base. In the right flank a nonpainful mass was palpable. Laboratory tests were performed: hematocrit $29.6 \%$, leukocytes $9.300 / \mathrm{mm}^{3}$, bacilli $372 / \mathrm{mm}^{3}$, platelet count $628.000 / \mathrm{mm}^{3}$, creatinine $0.6 \mathrm{mg} / \mathrm{dL}$, glucose $96 \mathrm{mg} / \mathrm{dL}$. Analysis of urine presented countless erythrocyte.
Computed tomography (CT) of abdomen showed a mass, involving almost completely the right kidney (Figure-1). The chest radiograph (Figure-2) and the CT scan demonstrated bilateral pleural effusion. Bone scintigraphy was negative for metastasis; the echocardiography was normal.

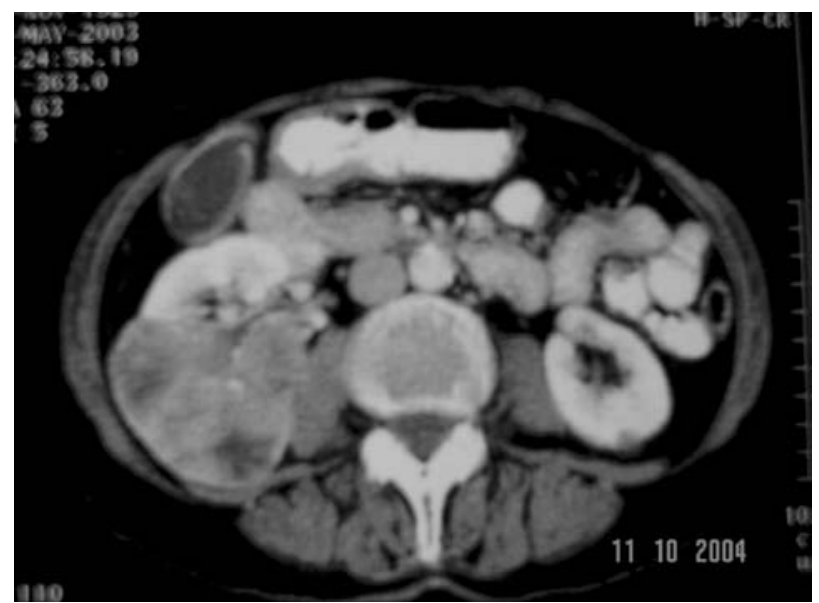

Figure 1 - Computed tomography (CT) of abdomen showing a mass, involving the right kidney almost completely. 


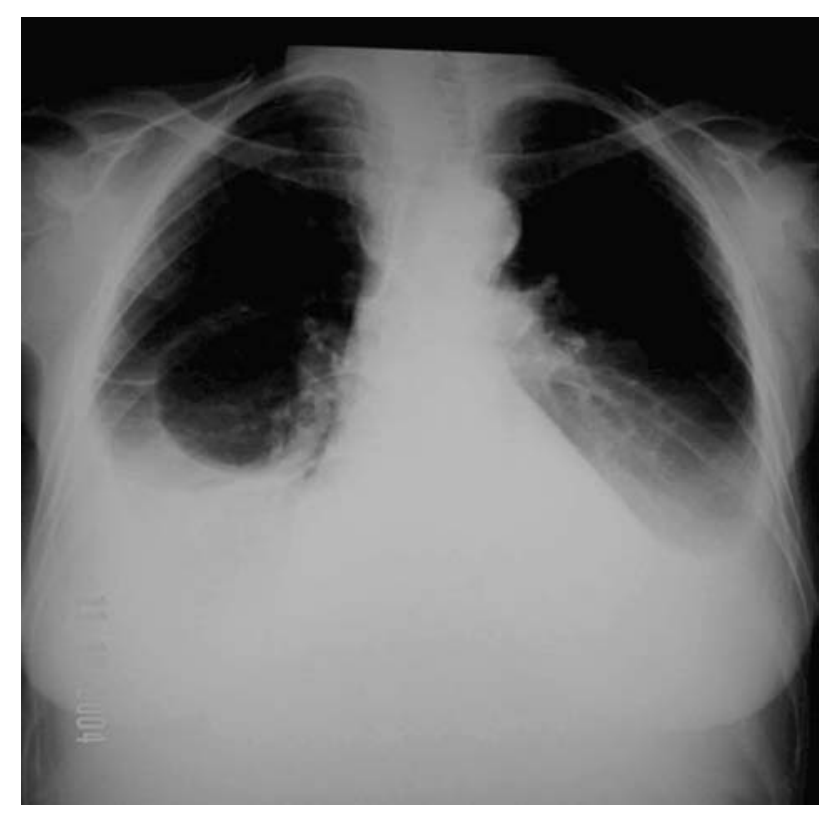

Figure 2 - Thorax $x$-ray showing bilateral pleural effusion.

Carrying out bilateral thoracocentesis. Gram, BAAR research, cultures of fungus and bacteria were all negatives. Results for total proteins were $3.5 \mathrm{~g} / \mathrm{dL}$ (serum $=5.5 \mathrm{~g} / \mathrm{dL}$ ) and the DHL was $156 \mathrm{u} / \mathrm{L}($ serum $=212 \mathrm{u} / \mathrm{L})$. Cytologic evaluation evidenced countless erythrocyte and absence of malignant cells. Diagnosis of the biopsy was bilateral chronic pleurisy. Two weeks after draining, patient's dyspnea returned. The CT scan evidenced pleural effusion. Therefore, the patient was submitted to a thoracoscopy, but there was no alteration in previous results.

Right nephroureterectomy was performed. The pathological result was renal pelvis transitional cell carcinoma; grade II of ASH. The patient had good postoperative evolution with complete pleural effusion disappearance.

After 7 months of postoperative, patient remained asymptomatic, with image tests without pleural liquid reaccumulation, or others alterations.

\section{COMMENTS}

Renal pelvis carcinomas more frequently metastasize in-continuity, but also by hematogenic and lymphatic routes. The most common locals of hematogenic dissemination are the liver, lungs, and bones (2). Although pulmonary metastasis is common, metastases to pleura, as well as pleural effusion, have not been described in association to transitional cell carcinoma.

The pleural effusion develops due to changes in the capillary hemodynamic; when appearing as an exudate suggests a local cause. Most of the times, the cause of the effusion becomes evident after a proper investigation. In the absence of post-pneumonic effusion, generalized hypoproteinemia or cardiac insufficiency, metastatic carcinoma, tuberculosis, pulmonary infarct, and mesothelioma must be excluded (2).

Once the above causes were excluded, 2 biopsies of pleura and 2 CT scanning were carried out to assure nonexistence of pleural metastases. Besides, the hemorrhagic appearance of the liquid could indicate the malignant nature; however, successive analyses of the liquid and biopsy had been all negative to the presence of malignant cells, attesting that the bloody liquid aspect did not demonstrate, necessarily, the presence of malignancy (2).

The pseudo-Meigs' syndrome has already been reported associated with many different tumors, but there was just one reported case associating the syndrome with renal neoplasm, in the literature (2).

The pseudo-Meigs' syndrome cases have in common the cure of the pleural effusion after the removal of the lesion. Such straight connection allows classifying different tumors as being the cause of only one syndrome $(1,3)$.

Therefore, the renal pelvis transitional cell carcinomacan result in the pseudo-Meigs' syndrome. The identification of such syndrome results in an accurate diagnosis, leading to an efficient surgical treatment, without comorbidity for the patient.

$\overline{\text { Professor Heitor A. Jammke }}$
contributed to this manuscript.

\section{REFERENCES}

1. Feldman ED, Hughes MS, Stratton P, Schrump DS, Alexander HR Jr: Pseudo-Meigs ‘syndrome secondary 
to isolated colorectal metastasis to ovary: a case report and review of the literature. Gynecol Oncol. 2004; 93: 248-51.

2. Dinney CP, Norman RW: Contralateral pleural effusion secondary to nonmetastatic renal cell carcinoma. J Urol. 1990; 143: 1002-3.
3. Ohsawa T, Ishida H, Nakada H, Inokuma S, Hashimoto D, Kuroda H, et al.: Pseudo-Meigs' syndrome caused by ovarian metastasis from colon cancer: report of a case. Surg Today. 2003; 33: 387-91.

Received: February 14, 2005 Accepted after revision: May 3, 2005

Correspondence address:

Dr. Chiara Scaglioni Tessmer

Av. São Francisco de Paula, 2592

Pelotas, RS, 96080-730, Brazil

Phone: +55 53 228-4199

E-mail: chiara_tessmer@yahoo.com.br 